\title{
Technical Safety Maintenance System (TeSaMa) in mechanical industry
}

\author{
TeSaMa - komputerowy serwis \\ utrzymania bezpieczeństwa technicznego w przemyśle mechanicznym
}

\section{MAREK DŹWIAREK *}

Web-based tool TeSaMa aims to provide a holistic approach for SME, giving them the ability to conduct and obtain risk assessments that include safety measure recommendations for production phase work places and machine development processes. This will enable the companies to fulfill legal requirements and improve productivity and reliability.

KEYWORDS: safety of machinery, conformity assessment, technical safety

In large enterprises - both public and private occupational health and safety management systems are significantly better developed than in small ones [1]. This is clearly visible in case studies, which indicate that the highest risk occurs in small enterprises. Also the number of post-accident absence days is significantly higher in smalland medium-sized enterprises [2-5].

Literature indicates a number of factors that may explain these disparities. Compared to large enterprises, SMEs do not have adequate financial resources or management procedures for health and safety management. Managers are often poorly involved in security-related activities, and informal and non-procedural approaches to prophylactic activities are ineffective [6-9].

The consequences of an accident can be devastating for a small enterprise. Short-term business interruptions can lead to loss of customers and important contracts, and one serious incident may mean business closure due to direct costs related to accident or loss of customers.

The study described in [10] assessed the legal actions against companies that were conducted after accidents in five EU countries in the last two years. Poland is the country with the highest rate of such activities, as they cover $16 \%$ of accidents. Another interesting fact is that $78 \%$ of companies in Germany with fatal accidents declare their willingness to revise risk analysis in workplaces, underlining the urgent need for professional and easily accessible risk assessment support [11].

An important issue for SMEs is the safety of machines designed and manufactured by them. Half of all accidents in the workplace occur in two sectors: construction (30\%) and

\footnotetext{
* Dr hab. inż. Marek Dźwiarek, prof. CIOP-PIB (madzw@ciop.pl) Centralny Instytut Ochrony Pracy - Państwowy Instytut Badawczy
}

industrial production (20\%) [12]. Enterprises in the machine sector, which play an important role as suppliers of machines or machine components to various production sectors, are often associated with accidents in the plants of their customers. If the accident is caused by a device failure or even by accidental misuse, compliance with the CE requirements, and in particular a correct and documented risk assessment of the machine, can protect the manufacturer from high legal costs.

These aspects were the basis for the development of the TeSaM computer service, which combines the issues of machine security management at the stage of their design and use.

\section{Research methodology}

The TeSaMa website was developed by a consortium comprising Fraunhofer IPT from Germany and CIOP-PIB from Poland and SME organizations: IFU - Institute for Management Cybernetics e. V. from Germany and DROMA - Association of Manufacturers of Machines, Devices and Tools for Wood Processing from Poland.

Research institutes were responsible for the implementation of the research program, and SME associations - for the supervision. The research methodology is shown in fig. 1.

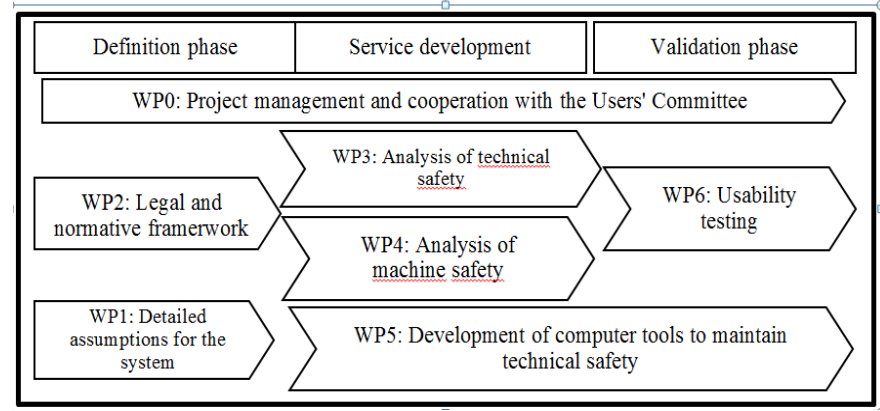

Fig. 1. Methodology of research when creating the TeSaM site

As part of the WPO task package, effective project management and cooperation of the contractors with the Users' Committee was ensured. Project management included the organization of information exchange between 
project partners and periodic meetings of the consortium and members of the Users' Committee.

The main purpose of the TeSaMa site is to support manufacturers and users of machines from the SME sector in the area of maintaining technical safety. In order to achieve this goal as effectively as possible, the work began with a detailed formulation of functional and program assumptions within the WP1 task package. The assumptions have been formulated based on a detailed analysis of existing, partial solutions. The development of the system concept was focused on determining the content of information on the website, the type of tools developed, the methodology of access to information by the system user and tools for evaluating his case. It included the exchange of experiences between system users, the selection of an IT platform and the formulation of rules for the management of user profiles.

The key issue in the development of the TeSaMa system was the detailed recognition of legal and normative requirements that should be met by the machinery sector enterprises. This applies to both pan-European and national regulations. The information obtained was collected on the website as a knowledge base. They also formed the basis for developing the required tools.

The largest number of accidents, and the most serious, in the engineering industry is related to the use of machines and other work equipment. In order to prevent accidents or at least minimize risk, all enterprises in the European Union are required to follow the recommendations of Directive 2009/104/EC regarding minimum health and safety requirements.

First of all, this means the obligation to carry out checks (preliminary, periodic, special) to meet the minimum requirements in order to monitor the current situation in various aspects of security [13]. Some of the identified case may require a risk assessment at workstations and in relation to the use of machines. As part of the WP3 task module, the recommended procedures for these controls and useful risk assessment methods were identified in the form of simple, intuitive tools and examples referring to the scope of their application. Newly manufactured machines should meet the safety requirements set out in the Machinery Directive 2006/42/EC. They involve the use of specific development and design procedures, including: detailed analysis of the manufacturing process in terms of security-related problems, risk assessment, selection and application of security measures, functional tests in industrial conditions close to real, implementation of the machine design and execution process as part of the quality system, development of necessary machine instructions and safety instructions, monitoring of safety-related events during machine operation and recording of actions taken to ensure safety.

The purpose of the WP4 task package was to provide machine manufacturers:

- knowledge of procedures supporting the fulfillment of essential requirements in accordance with Directive 2006/42/EC and selected harmonized standards,

- simple tools allowing to assess risk for machine sector products and document the results of this assessment,

- examples illustrating these activities.

Currently, Internet is the most effective way to provide IT support tools. The WP5 task package was designed to develop a fully functional IT tool supporting the maintenance of technical safety in the engineering industry, providing the necessary and transparent knowledge resource. It is intended to contain simple tools supporting activities related to health and safety at work undertaken in enterprises, especially those related to the fulfillment of legal requirements, and providing useful examples of problem solving.
The correctness of the developed system has been verified by testing usability with two methods: expert inspection (EI) and user testing (UT) [14] as part of the WP6 package.

\section{Results}

- Development of detailed assumptions for the system concept. The detailed assumptions of the TeSaMa site were developed based on the review of over 100 websites devoted to the issues of maintaining technical safety in manufacturing enterprises. Among them were websites containing publications, guides, discussions and suggestions, especially in the area of occupational risk and maintenance. The number of programs supporting the risk assessment is also quite significant. The offer of on-line tools is limited.

Fig. 2 presents the advantages of the analyzed websites.

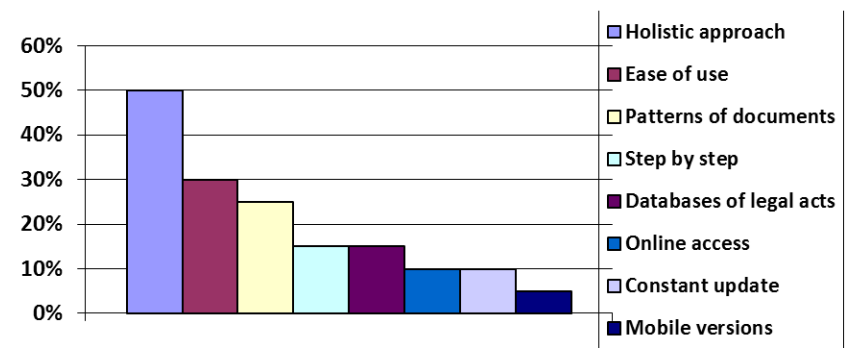

Fig. 2. List of advantages of the analyzed websites

A questionnaire was also conducted in over 100 enterprises involved in the production of machines on their preferences and needs in the area of tools supporting the maintenance of technical safety. Examples of answers to the question: "In your opinion, what kind of functionalities may be most useful to support the technical safety of new machines? Rate usability on a scale from 1 (smallest) to 8 (greatest)" shown in fig. 3 .

Based on the requirements of the Polish Users' Committee, it was agreed that the tool should have specific modules for woodworking machines. However, on the basis of the requirements of the User Committee from Germany, detailed modules for machines in which lasers are used have been introduced.

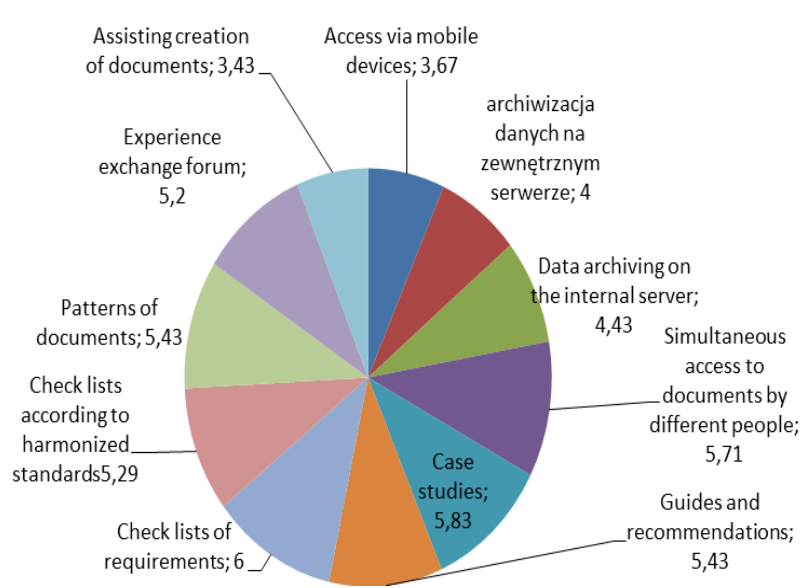

Fig. 3. Sample results of a survey conducted among enterprises

- System construction. At the same time, available IT tools were analyzed and software and hardware assumptions were developed. It was established that the service should be able to be operated by both desktop computers, as well as portable computers, smartphones and tablets. 
The developed methods and principles have been implemented on the website. All pro-grammar work was consulted on an ongoing basis with the authors of tools and methodologies. As a result, inconsistencies and imperfections were identified and removed from the software development stage, both in the developed methods and in their program implementation.

- System validation. As part of the testing, five experts carried out an attempt to use the developed tools to evaluate four different machines and the safety component, which was an emergency stop controller. In this way, all modules and tools have been meticulously checked. In the case of general modules, it was done five times. Each expert submitted comments on the form developed for this purpose. The collected remarks were introduced as improvements to the system.

The final verification of the system was carried out by its future users - from three Polish and two German companies. They put their opinion on questionnaires prepared for the evaluation of the TeSaM service as an adaptation of the TAM questionnaires (Technology Acceptance Model [15]) and SUS (System Usability Scale) questionnaires. The results of the survey showed that the system is useful, although the formal requirements resulting from the regulations are quite complex. In the majority of questions concerning the usability, friendliness and adequacy of average ratings, it ranged around 5 points out of 7 possible. This allows confirmation of the acceptance of the developed technology by users.

\section{Conclusions}

The computer service developed within the TeSaMa project, supporting the maintenance of technical safety in the engineering industry, will facilitate the implementation of activities related to the assessment of their work equipment as well as conformity assessment of manufactured machines. The cost of using the system by SMEs, ignoring the work related to obtaining information about standards and regulations, will be negligible.

In Poland - according to the statistical year - in 2010 there were about 1,400 companies manufacturing machines. All these enterprises are the target audience of project results.

Parallel to substantive activities, dissemination activities were carried out. They mainly concerned the presentation of the system at conferences, fairs and seminars. Promotional leaflet of the project, printed in a circulation of 10,000 copies were disseminated during trade fairs and in the Kurier Drzewny magazine.

Publication based on the project results "TeSaMa System for maintaining technical safety in the mechanical industry", implemented as part of the Opening National and Regional Programs for Transnational Collective Research between SME Associations and Research Organizations, CORNET $14^{\text {th }}$ Call for Proposals, in 2013-2015, co-financed with National Center for Research and Development.

\section{REFERENCES}

1. Sorensen O.H., Hasle P., Bach E. "Working in small enterprises - is there a special risk". Safety Sci. 45, 10 (2007): pp. 1044-1059.

2. Fabiano B., Curro F., Pastorino R. "A study of the relationship between occupational injuries and firm size and type in the Italian industry". Safety Science. 42, 7 (2004): pp. 587-600.
3. Stevens G. "Workplace injuries in small and large manufacturing workplaces - An analysis of the risks of fatal and non-fatal injuries, including figures for 1994/5-1995/6". Features. Labour Market Trends. 107 (1999)

4. Mayhew C. "OHS in Australian «micro» small businesses evidence from nine research studies". Journal of Occupational Health and Safety. Australia and New Zeland. 16, 4 (2000): pp. 297-305.

5. McVittie D., Banikin H., Brocklebank W. "The effect of firm size on injury frequency in construction". Safety Science. 27, 1 (1997): pp. 19-23.

6. Mayhew C. "Barriers to Implementation of Known Occupational Health and Safety Solutions in Small Businesses". Australian Government Publishing Service, Canberra, 1997.

7. Rigby M., Lawlor T. "Health and safety in small firms with particular reference to Spain". International Small Business Journal. 19, 2 (2001): pp. 31-48.

8. Champoux D., Brun J.P. "Occupational health and safety management in small size enterprises - An overview of the situation and avenues for intervention and research". Safety Science. 41 (2003): pp. 301-318.

9. Lamm F., Walters D. "OHS in small organizations - Challenges and ways forward". Regulation for a Changing Word of Work. The Australia: Federation Press, 2003.

10. European Agency for Safety and Health at Work. "Occupational safety and health and economic performance in small and mediumsized enterprises-a review". Luxembourg, 2009.

11. Bundesanstalt für Arbeitsschutz und Arbeitsmedizin: Gefährliche Produkte 2012 - Informationen zur Produktsicherheit. Dortmund/Berlin/Dresden (2012).

12. Angermann A., Bauer R., Nossek G., Zimmermann N. "Injuries In The European Union - Statistics summary 2003-2005". Kuratorium für Verkehrssicherheit, Vienna, 2007.

13. Dźwiarek M., Hryniewicz O. „Practical examples of determination of periodical inspection of safety related control systems of machinery". Przegląd Elektrotechniczny. 88, 5A (2012): pp. 290-295.

14. Bach C., Scapin D.L. "Comparing Inspections and User Testing for the Evaluation of Virtual Environments". Intl. Journal of HumanComputer Interaction. 26, 8 (2010): pp. 786-824.

15. Venkatesh V., Davis F. "A theoretical extension of the technology acceptance model: Four longitudinal field studies". Management Science. 46, 2 (luty, 2000): pp. 186-204.

Translation of scientific articles, their computer composition and publishing them on the website www.mechanik.media.pl by original articles in Polish is a task financed from the funds of the Ministry of Science and Higher Education designated for dissemination of science.

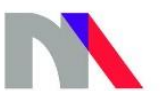

Ministry of Science and Higher Education Republic of Poland 